valproate exposure. These findings are in contrast to the absence of delayed cognitive performance in children exposed in utero to levetiracetam.

\title{
PREVALENCE OF VIGABATRIN-INDUCED VISUAL FIELD LOSS
}

The magnitude of risk of vigabatrin-associated visual field loss and any clinical predictors of risk were determined by systematic review of 32 studies identified by electronic searches of the literature. Reports were analyzed at the Universities of Liverpool, Cardiff, Birmingham, and Warwick, Coventry, UK. Of 1,678 patients exposed to vigabatrin, $738(44 \%)$ had visual field loss compared to $30(7 \%)$ among 406 controls. The random-effects estimate for the proportion of children with visual field loss was $34 \%$ compared to $52 \%$ for adults. The relative risk for visual field loss was 4.0 . Risk factors for a higher proportion of patients with visual field loss were a larger mean cumulative dose of vigabatrin and increasing age. The authors conclude that vigabatrin should be reserved for patients with epilepsies known to be unresponsive to other alternative therapies or for patients receiving benefit from vigabatrin that outweighs the risk. (Maguire MJ, Hemming K, Wild JM, Hutton JL, Marson AG. Prevalence of visual field loss following exposure to vigabatrin therapy: A systematic review. Epilepsia Dec 2010;51(12):2423-2431). (Respond: Dr Melissa Maguire, Newcastle General Hospital, Westgate Rd, Newcastle-upon-Tyne, NE4 6BE, UK. E-mail: maguirem@doctors.org.uk).

COMMENT. Vigabatrin, an analog of GABA, irreversibly inhibits GABA transaminase, and increases brain levels of GABA. Bilateral concentric constriction of visual fields with relative sparing of the temporal fields, first reported in 1997, affects one third of children and one half of adults treated with vigabatrin. Apart from age, male gender, and cumulative dose over time, risk factors for this adverse effect of vigabatrin are unknown. Its use in children is restricted to patients with infantile spasms and tuberous sclerosis and as adjuvant therapy for partial seizures refractory to alternative treatments. Visual field examination is required prior to and at intervals during treatment. The intervals and optimal frequency of perimetry has not been determined. Ongoing research concerning risk factors and early detection of visual field loss associated with vigabatrin includes a possible genetic predisposition and use of imaging as a biomarker of nasal retinal nerve fiber attenuation (Moseng L et al. Acta Ophthalmol Jan 21, 2011;10:1111). Several studies show that the visual field loss may be permanent.

\section{SEIZURE DISORDERS}

\section{REVISED AAP PRACTICE GUIDELINES FOR EVALUATION OF THE CHILD WITH A SIMPLE FEBRILE SEIZURE}

An AAP subcommittee on febrile seizures has revised the practice guidelines of 1996 for the diagnosis and evaluation of a simple febrile seizure in children 6 months through 60 months of age. Articles published since the last guideline through 2009 were reviewed, and recommendations were assessed until consensus was reached. The committee notes that the following do not indicate an exclusive course of treatment, and variations according to individual circumstances may be appropriate: 